\title{
Sistem Pemantauan dan Pendeteksi Kebakaran berbasis Logika Fuzzy dan Real-time Database
}

\author{
EVA AISAH HW, ROHMAT TULLOH, SUGONDO HADIYOSO, \\ DADAN NUR RAMADAN
}

\author{
Fakultas Ilmu Terapan, Universitas Telkom, Bandung \\ Email: evaaisahhw@gmail.com
}

Received 21 Januari 2021 | Revised 2 Februari 2021 | Accepted 27 Maret 2021

\begin{abstract}
ABSTRAK
Kebakaran rumah seringkali disebabkan oleh kelalaian manusia. Oleh karena itu diperlukan sebuah sistem yang dapat mendeteksi kebakaran secara online realtime. Pada studi ini, dirancang dan diimplementasikan sebuah sistem pendeteksi kebakaran dengan sejumlah sensor untuk mengukur beberapa parameter lingkungan. Sistem ini dilengkapi dengan pengambil keputusan menggunakan metode fuzzy logic. Parameter lingkungan yang diukur mencakup suhu ruangan, asap dan api yang kemudian dapat dimonitor secara real-time melalui web interface menggunakan Internet of Things platform. Pengujian menunjukkan bahwa detektor dapat mendeteksi api dengan jarak hingga $100 \mathrm{~cm}$ dengan akurasi mencapai 100\%. Pengujian sensor suhu menunjukkan akurasi 98.79\%, sementara itu detektor asap memperoleh akurasi $77.81 \%$. Sistem ini mampu mengirimkan data dengan rata-rata delay transmisi 0.62 detik. Sistem usulan ini diharapkan dapat menyediakan pemantauan kondisi suatu ruangan secara real-time.
\end{abstract}

Kata kunci: Kebakaran, Real-Time, Deteksi, Fuzzy, Internet Of Things

\begin{abstract}
House fires are often caused by human error. Therefore, we need a system that can detect fires online real-time. In this study, a fire detection system with a number of sensors is designed and implemented to measure several environmental parameters. This system is equipped with a decision maker using the fuzzy logic method. The environmental parameters measured include room temperature, smoke and fire which can then be monitored in real time via a web interface using the Internet of Things platform. Tests show that the detector can detect fires with a distance of up to $100 \mathrm{~cm}$ with an accuracy of up to $100 \%$. The temperature sensor test shows an accuracy of $98.79 \%$, while the smoke detector generates an accuracy of $77.81 \%$. This system is capable of sending data with an average transmission delay of 0.62 seconds. This proposed system is expected to provide realtime monitoring of the condition of a room.
\end{abstract}

Keywords: Fire, Real-time, detection, Fuzzy, internet of things 
Aisah, dkk

\section{PENDAHULUAN}

Keselamatan dalam sebuah rumah merupakan hal utama yang wajib menjadi perhatian, ancaman bahaya yang mungkin terjadi harus dapat dideteksi sedini mungkin, sehingg tidak membahayakan para penghuni rumah, salah satunya yaitu kebakaran yang terkadang disebabkan oleh kelalaian manusia (Addawiyah \& Windraswara, 2016). Adanya kerugian yang diakibatkan oleh bencana kebakaran, seperti harta benda, bahkan korban jiwa (Farokhi, 2019). Berdasarkan data dari Dinas Pemadam Kebakaran dan Penanggulangan Bencana (DPKPB) Kota Bandung mencatat ada sebanyak 200 peristiwa kebakaran telah terjadi di Kota Bandung dalam kurun waktu Januari hingga Juli 2018 (Dinas Kebakaran, 2017).

Berdasarkan uraian permasalahan diatas, maka diperlukan sistem yang dapat mendeteksi dan memberikan peringatan dini mengenai kondisi sebuah rumah secara realtime (Hidayat, dkk, 2018)(Juanita \& Windarto, 2017). Sistem ini dapat menggunakan mikrokontroler yang terintegrasi dengan sebuah website dan input berupa sensor yang dapat mengukur suhu, kualitas udara, dan situasi adanya api atau tidak sebagai langkah antisipasi adanya kebakaran. Sistem ini harus menggunakan konsep realtime agar bisa mengetahui kondisinya setiap saat (Damanik, dkk, 2020)(Hartawan \& Sudiarsa, 2019)(Nusa, dkk, 2015). Implementasi sistem serupa yaitu sistem monitoring dan otomatisasi perangkat rumah telah dilaporkan pada beberapa studi (Prihatmoko, 2018)(Rizal \& Karyana, 2019). Sistem ini mampu memonitor dan mengendalikan sejumlah perangkat kelistrikan pada rumah. Beberapa studi lainnya merealisasikan sistem monitoring dan deteksi kebakaran seperti yang dilaporkan pada (Imamuddin, 2019)(Putra, dkk, 2018). Namun demikian, pengambilan keputusan belum mempertimbangkan sejumlah parameter dari sejumlah sensor.

Pada studi ini, diusulkan sebuah sistem pendeteksi kebakaran yang dapat memberikan peringatan dini sebelum terjadinya kebakaran secara realtime. Sistem ini dapat digunakan oleh pemilik rumah sebagai langkah antisipasi terjadinya sebuah kebakaran yang mungkin saja terjadi karena lupa mematikan sebuah kompor, adanya gas berbahaya, dan suhu tinggi. Berdasarkan pada penelitian sebelumnya oleh Firman Al Rahmat dkk, dimana merealisasikan prototipe robot kapal pengukur tingkat keasaman dan turbiditas air berbasis metode modified fuzzy (Rahmat, dkk, 2018). Maka pada studi ini dikembangkan sebuah sistem monitoring dengan menggunakan pendekatan fuzzy logic sebagai penentu kondisi ruang dalam rumah. Sistem ini merupakan sebuah prototipe pendeteksi kebakaran rumah dengan pembacaan sensor api, asap, dan suhu yang kemudian akan diolah untuk penentuan kondisi menggunakan fuzzy logic. Kemudian data ditampilkan pada sebuah website monitoring yang akan menampilkan data secara realtime. Perbedaannya yaitu pada pembacaan sensor, sistem pengiriman data dan website yang digunakan untuk menampilkan data dan kondisi secara realtime.

Sistem yang diusulkan ini merupakan sistem embedded yang terdiri dari hardware dan software. Hardware pada sistem pendeteksi kebakaran menggunakan NodeMCU ESP8266 yang terintegrasi dengan flame sensor, DHT-22, MQ-2, Buzzer dan OLED Display. Software dalam sistem pendeteksi kebakaran berupa media website. Data yang diperoleh bersifat realtime dengan fitur firebase realtime database sehingga pemantauan kebakaran yang diterima oleh user melalui media website selalu update. Dengan adanya Sistem Pemantauan dan Pendeteksi Kebakaran, maka proses terjadinya kebakaran dapat diketahui sedini mungkin dan dapat dicegah, berdasarkan informasi yang diberikan oleh sensor, yaitu dengan adanya api, timbulnya asap atau perubahan suhu dan kelembapan yang dratis didalam ruangan yang terpasang perangkat dengan sistem ini. 


\section{PERANCANGAN DAN IMPLEMENTASI SISTEM}

Sistem yang dibuat terdiri dari hardware dan software yang digunakan untuk melakukan pemantauan pada Dapur secara realtime. Hardware pada sistem pendeteksi kebakaran menggunakan metode fuzzy logic berbasis Internet of Things dengan media informasi berupa website. Adapun blok diagram dari Sistem Pendeteksi Kebakaran seperti pada Gambar 1 berikut ini:

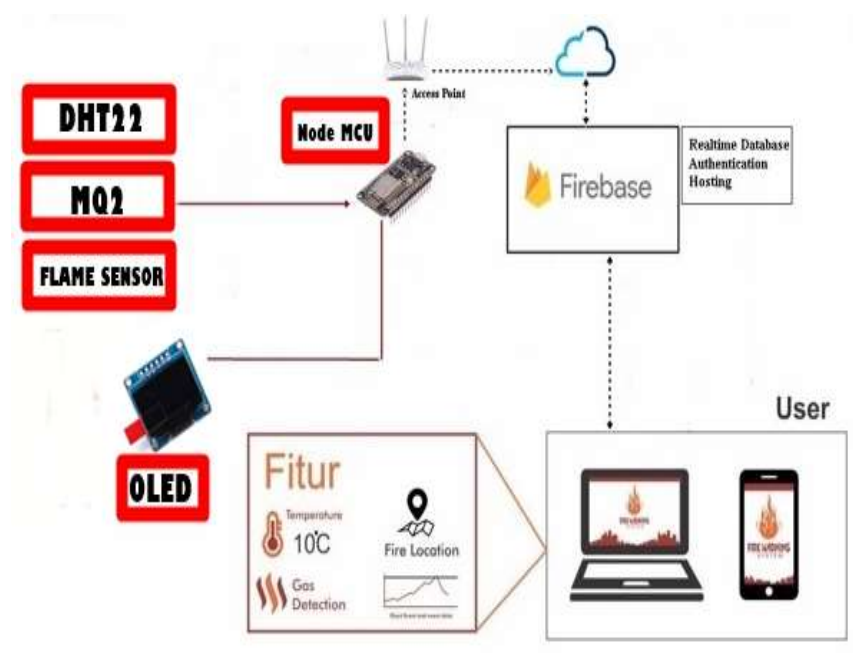

Gambar 1. Blok Diagram sistem

Berdasarkan Gambar 1, data pemantauan kondisi keamanan kebakaran dapur yang diperoleh meliputi pendeteksian api, suhu, dan kelembapan. Nilai keluaran yang didapatkan oleh hardware akan dikirim ke Firebase Realtime Database dan ditampilkan dengan media website serta indikator OLED Display pada sisi hardware. Apabila suatu ruangan memiliki kondisi potensi kebakaran yang terdeteksi melalui hardware pada Sistem Pendeteksi Kebakaran maka sistem secara otomatis mengirimkan data lokasi pada website.

\subsection{Perancangan Fuzzy Logic}

Metode Fuzzy Logic yang digunakan pada Sistem Pendeteksi Kebakaran yaitu metode Sugeno. Fuzzy Logic ini digunakan untuk memproses data hasil pengukuran dari sensor DHT22 berupa suhu, MQ-2 berupa asap, Flame berupa api. Hasil defuzzifikasi pada suhu, asap, dan api merupakan parameter untuk kondisi keamanan kebakaran pada Sistem Pendeteksi Kebakaran di Dapur. Tahapan proses metode fuzzy logic pada Sistem Pendeteksi Kebakaran seperti pada Gambar 2 berikut ini:

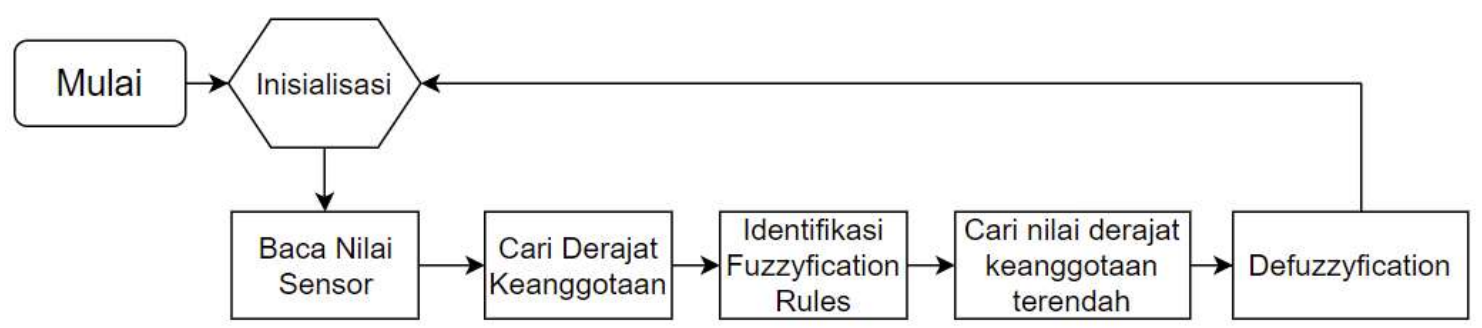

Gambar 2. Proses Metode Fuzzy Logic 
Fuzzifikasi merupakan proses perubahan nilai data dari setiap sensor menjadi bentuk himpunan fuzzy berdasarkan fungsi keanggotaannya, proses ini berfungsi untuk menempatkan setiap nilai sesuai dengan derajat keanggotannya, yaitu 0 dan 1 . Apabila nilai yang berada di antara 0 dan 1, maka disebut samar ( fuzzy)(Cahyadi, dkk, 2020; Satriatama, dkk, 2020). Hardware kemudian mendapatkan nilai suhu, kelembapan, dan api sebagai crisp input pada fuzzy logic. Selanjutnya, Fuzzifikasi akan membuat fungsi keanggotaan dan menentukan banyaknya linguistic variable. Berdasarkan fungsi keanggotaan tersebut akan dapat diketahui nilai derajat keanggotaan setiap variable dalam himpunan fuzzy yang telah dibuat berdasarkan fungsi keanggotaannya. Hasil dalam bentuk grafik dari fungsi keanggotaan suhu yang digunakan memiliki 3 variabel linguistic yaitu Dingin, Hangat dan Panas. Dengan range nilai dingin dari $0^{\circ} \mathrm{C}$ sampai $20^{\circ} \mathrm{C}$, range nilai hangat diantara $20^{\circ} \mathrm{C}$ sampai dengan $55^{\circ} \mathrm{C}$ dan range nilai panas diatas $48^{\circ} \mathrm{C}$. Seperti pada gambar 3 dibawah ini.

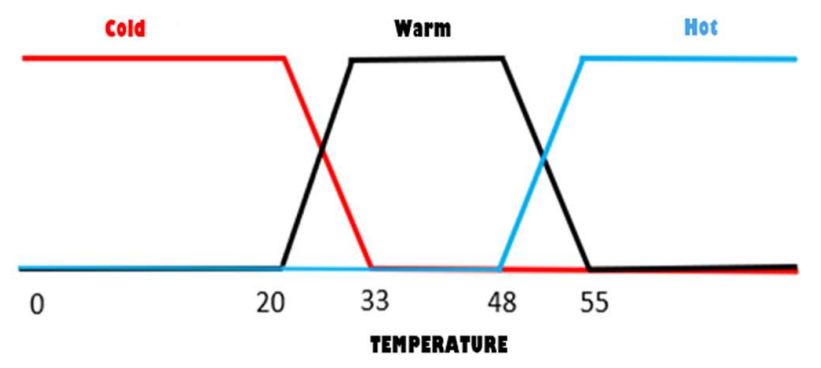

Gambar 3. Fuzzifikasi suhu

Bentuk grafik dari fungsi keanggotaan asap yang digunakan memiliki 3 variabel linguistic yaitu Low, Medium dan High. Dengan range Low dari 0 ppm sampai 200 ppm, range medium diantara 200 ppm sampai dengan 5500 ppm dan range nilai panas diatas 4500 ppm.

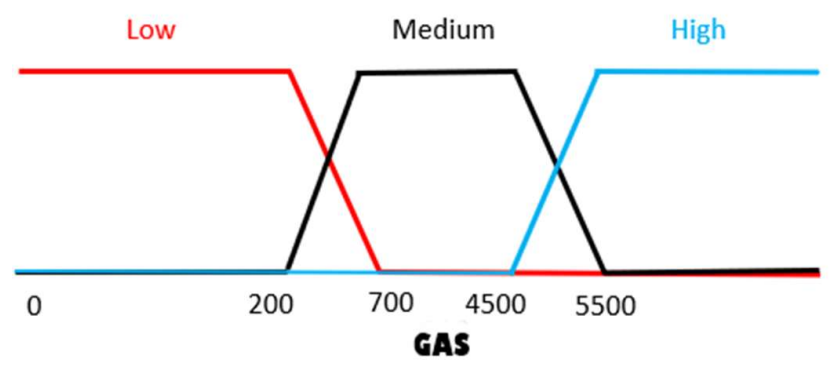

\section{Gambar 4. Fuzzifikasi asap}

Hasil dalam bentuk grafik dari fungsi keanggotaan api yang digunakan memiliki 2 variabel linguistic yaitu Low dan High. Dengan range Low sebesar 0 dan range nilai High sebesar 1. 
Sistem Pemantauan dan Pendeteksi Kebakaran Berbasis Logika Fuzzy dan Real-time Database

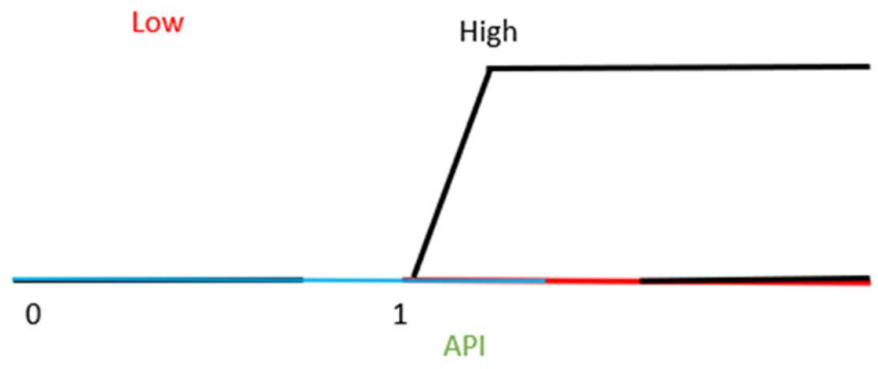

Gambar 5. Fuzzifikasi api

Fuzzy Rules dibuat berdasarkan logika, intuisi serta percobaan tryand errorsetelah melakukan tes manual terhadap perubahan suhu, adanya asap dan api di Dapur yang akan digunakan. Fuzzy rules bersifat subjektif. Fuzzy rules digunakan untuk menghubungkan antara setiap variabel-variabel masukan kepada sistem dengan variabel-variabel keluaran dari sistem, aturan ini berbentuk if-then rules. Tabel Fuzzy Rules pada sistem pendeteksi kebakaran seperti pada Tabel 1 berikut ini:

Tabel 1. Fuzzy Rules

\begin{tabular}{|c|c|c|c|}
\hline No. & Temperature & Asap & Output \\
\hline 1. & Cold & Low & Safe \\
\hline 2. & Cold & Medium & Safe \\
\hline 3. & Cold & High & Warning \\
\hline 4. & Warm & Low & Safe \\
\hline 5. & Warm & High & Warning \\
\hline 6. & Warm & Low & Warning \\
\hline 7. & Hot & Medium & Warning \\
\hline 8. & Hot & High & Warning \\
\hline 9. & Hot & Medium & Warning \\
\hline 10. & Cold & High & Safe \\
\hline 11. & Cold & Low & Warning \\
\hline 12. & Cold & Medium & Safe \\
\hline 13. & Warm & High & Danger \\
\hline 14. & Warm & Low & Danger \\
\hline 15. & Warm & Medium & Danger \\
\hline 16. & Hot & High & Danger \\
\hline 17. & Hot & & Danger \\
\hline 18. & Hot &
\end{tabular}

Berdasarkan Tabel 1 diatas menunjukkan bahwa terdapat 18 kondisi pada sistem pendeteksi kebakaran yang dibuat untuk menentukan status keamanan kebakaran pada dapur. Penentuan kondisi pada fuzzy rules seperti pada Tabel 2 berikut ini:

Tabel 2. Threshold Fuzzy Rules

\begin{tabular}{|c|c|c|c|}
\hline \multicolumn{4}{|c|}{ THRESHOLD } \\
\hline & LOW & MEDIUM & HIGH \\
\hline TEMP & $<20^{\circ} \mathrm{C}$ & $33-48^{\circ} \mathrm{C}$ & $>55^{\circ} \mathrm{C}$ \\
\hline FIRE & 0 & & 1 \\
\hline Smoke & $<200 \mathrm{ppm}$ & $200-5000 \mathrm{ppm}$ & $>5000 \mathrm{ppm}$ \\
\hline
\end{tabular}


Proses defuzzifikasi menggunakan metode weighted average. Metode weighted average merupakan metode pengambilan rata-rata menggunakan pembobotan dari fuzzy set berupa derajat keanggotaan, persamaan Defuzzifikasi seperti berikut ini:

$$
\mathrm{y}^{*}=\frac{\sum y \mu R(y)}{\sum y \mu R(y)}
$$

Dimana y adalah nilai crips dan $\mu(\mathrm{y})$ adalah derajat keanggotaan dari nilai crips y. Tahap terahir dari fuzzy logic yaitu defuzzifikasi. Setelah dibuat rules tersebut maka akan muncul grafik yang menyatakan hasil yang diharapkan berdasarkan fuzzy rules dan nilai masukan yang difuzzyfikasi sebelumnya. Pengelompokan kondisi status keamanan kebakaran terdiri dari Safe dengan defuzzifikasi sebesar 1 , Warning dengan defuzzifikasi sebesar 0.5, dan Danger dengan defuzzifikasi sebesar 0, persamaan Fuzzifikasi ditampilkan pada script pemprograman berikut:

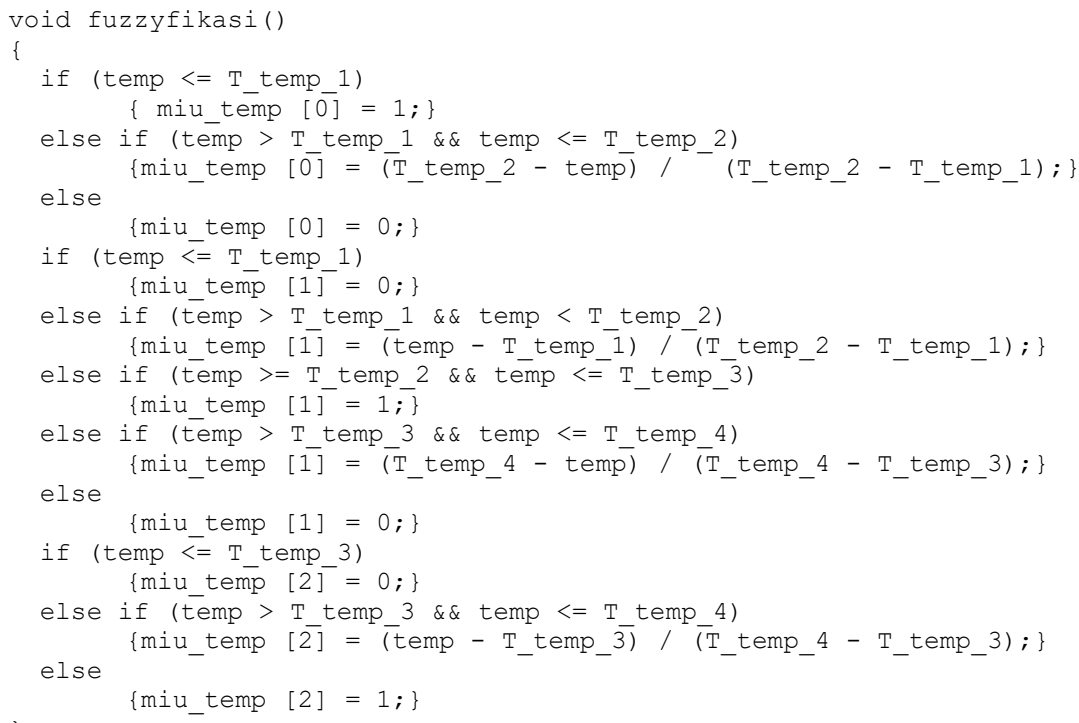

\subsection{Realisasi Hardware}

Gambar 6 menunjukkan blok diagram bagian hardware dari usulan sistem. Sistem ini memiliki komunikasi satu arah yaitu nilai masukan dari sensor berupa pendeteksian api, suhu, dan kelembapan. Hardware pada sistem pendeteksi kebakaran menggunakan microcontroller NodeMCU ESP8266 sebagai pemrosesan data.

Selanjutnya akan diproses pada mikrokontroler NodeMCU ESP8266 menggunakan fuzzy logic sebagai parameter algoritma pemrograman pada sistem pendeteksi kebakaran. NodeMCU ESP8266 terhubung dengan jaringan Internet yang telah disediakan dengan operator. Data pemantauan pendeteksian api, suhu, dan kelembapan yang diperoleh oleh Hardware akan ditampilkan pada OLED Display dan dikirimkan ke Firebase Realtime Database.

Perancangan komponen elektronika pada sensor DHT-22 yang digunakan untuk mengukur suhu dan kelembapan pada sistem pendeteksi kebakaran mendapatkan catu daya DC 3V, Ground, dan D5 (Digital) dari NodeMCU ESP8266. Pin DAT pada sensor DHT-22 dihubungkan dengan pin D5 untuk memberikan nilai masukan digital pada sistem pendeteksi kebakaran, nilai masukan sensor DHT-22 dalam pengukuran suhu dan kelembapan menggunakan tipe data float. Tipe data float merupakan tipe data numerik dengan angka desimal. Nilai suhu dan kelembapan didapatkan dengan pembacaan pin D5 pada NodeMCU ESP8266. 


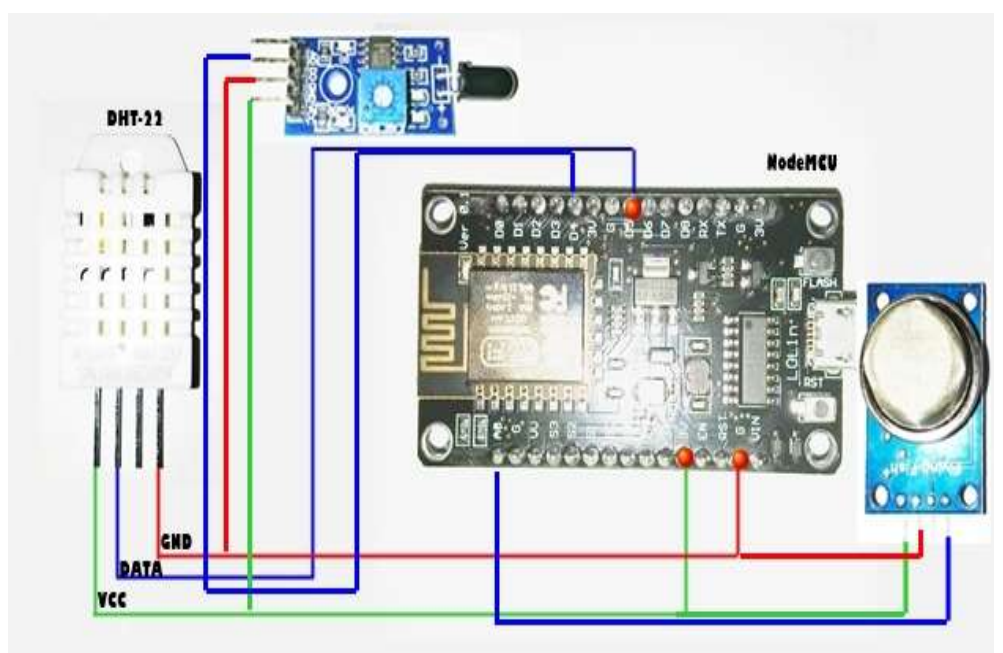

Gambar 6. Schematic hardware pada sistem pendeteksi kebakaran

Flame sensor dalam deteksi Api pada sistem ini dimulai dari inisialisasi variable. Nilai deteksi api pada Flame sensor akan dikelompokkan fuzzifikasi dengan kondisi nilai api sebesar 1 dan nilai kondisi tidak terdapat api yaitu 0 . Setelah proses fuzzifikasi maka sistem akan mencari nilai rata-rata minimum berdasarkan rules fuzzy logic yang digunakan untuk pendeteksian api. Setelah proses mencari nilai minimum dan rata-rata maka akan dilakukan defuzzifikasi untuk mencari nilai akhir kondisi api yang disebut sebagai status. Status pada kondisi Api digunakan untuk menentukan parameter keamanan kebakaran. Perancangan komponen elektronika pada Flame Sensor yang digunakan untuk pendeteksian api pada sistem pendeteksi kebakaran mendapatkan catu daya DC 3V, Ground, dan D6 (Digital) dari NodeMCU ESP8266. Pin D0 pada Flame Sensor dihubungkan dengan pin D6 untuk memberikan nilai masukan digital pendeteksian Api.

Hasil pengukuran asap oleh MQ-2 dilakukan fuzzifikasi dengan nilai asap sebesar 0 sampai 1 . Setelah proses fuzzifikasi maka sistem akan mencari nilai minimum dan nilai rata-rata asap berdasarkan rules fuzzy logic. Setelah proses mencari nilai minimum dan rata-rata pada asap maka akan dilakukan defuzzifikasi untuk mencari nilai akhir kondisi asap yang disebut sebagai status. Status pada kondisi asap digunakan untuk menentukan parameter keamanan kebakaran. Perancangan komponen elektronika pada Sensor MQ-2 yang digunakan untuk pengukuran asap pada Sistem Pendeteksi Kebakaran mendapatkan catu daya DC 3V, Ground, dan A0 (Analog) dari NodeMCU ESP8266. Pin A0 pada Sensor MQ-2 dihubungkan dengan pin A0 di NodeMCU ESP8266 untuk memberikan nilai masukan analog 0 - 10000 di pengukuran asap pada sistem pendeteksi kebakaran.

\subsection{Desain Wadah Perangkat Keras dan Rancangan Aplikasi}

Perangkat keras pendeteksi kebakaran yang telah direalisasikan kemudian ditempatkan pada box berbahan akrilik dengan dimensi $10 \times 10$ × $20 \mathrm{~cm}$. Gambar 9 menunjukkan tata letak perangkat keras pada kotak akrilik. 


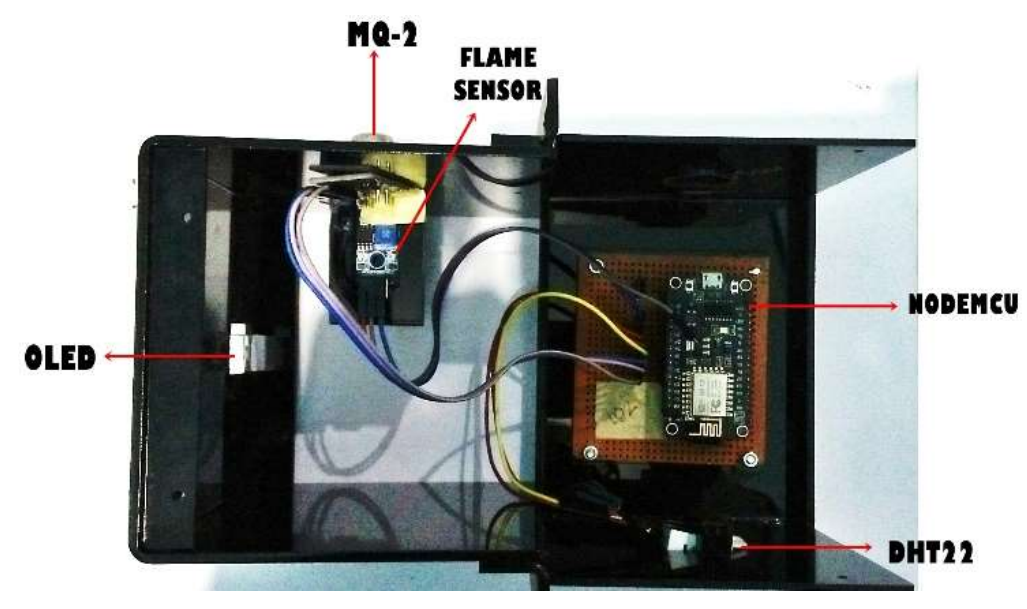

Gambar 9. Mekanik komponen elektronika

Perancangan program aplikasi pada usulan system ini dirancang menggunakan framework realtime database berupa media website. Tampilan website aplikasi disajikan pada Gambar 10, dimana Gambar 10. (a) tampilan dashboard website, sementara itu Gambar 10. (b) adalah tampilan setelah login berhasil dan Gambar 10. (c) adalah tampilan setelah login admin.

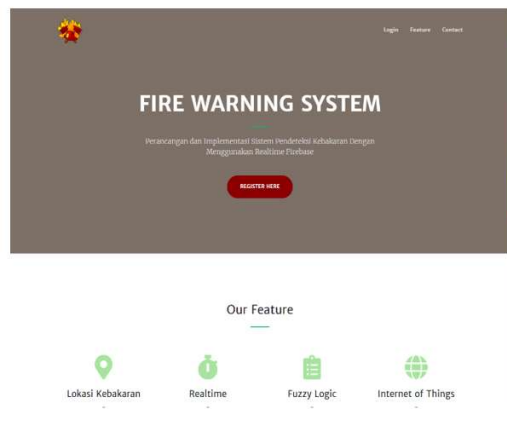

A

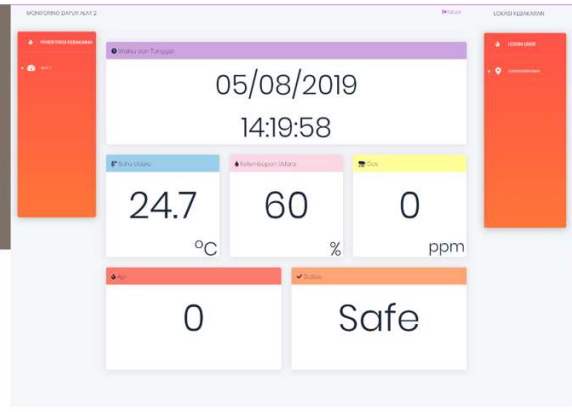

B

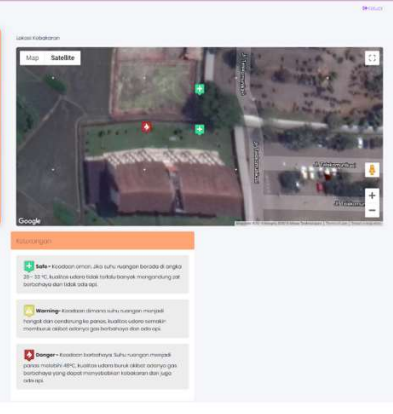

C

\section{Gambar 10. (a) Tampilan dashboard website, (b) tampilan setelah login user, (c) tampilan setelah login admin}

Dalam menjalankan aplikasi ini, terdapat dua hak akses atau kewenangan meliputi admin dan user. Admin adalah pengelola layanan dan mempunyai hak penuh atas data dan pengaturan aplikasi. Sementara itu user adalah penggunan pasif yang hanya dapat melihat data sensor. Beriku adalah penjelasan detail berkaitan dengan hak akses untuk dua kategori tersebut.

1. Admin dapat melihat data sensor, serta mengetahui indikator keamanan kebakaran dari ruangan yang telah terpasang perangkat. Pengelolaan data keamanan kebakaran dan Hardware sebagai admin tersebut dapat dilakukan setelah login sebagai admin.

2. User dapat melihat data-data sensor yang berada di seluruh ruangan, hal ini dapat dilakukan setelah melakukan login pada halaman website khusus user. 


\section{HASIL DAN DISKUSI}

Sistem ini telah diimplementasikan dan diujikan di dua tempat berbeda dengan luas dapur sebesar $2.6 \mathrm{~m} 2$ dan $6 \mathrm{~m} 2$. Dimensi hardware ini sebesar $10 \mathrm{~cm} \times 10 \mathrm{~cm} \times 10 \mathrm{~cm}$, dengan cara kerja sistem ini ditunjukkan pada Gambar 11.

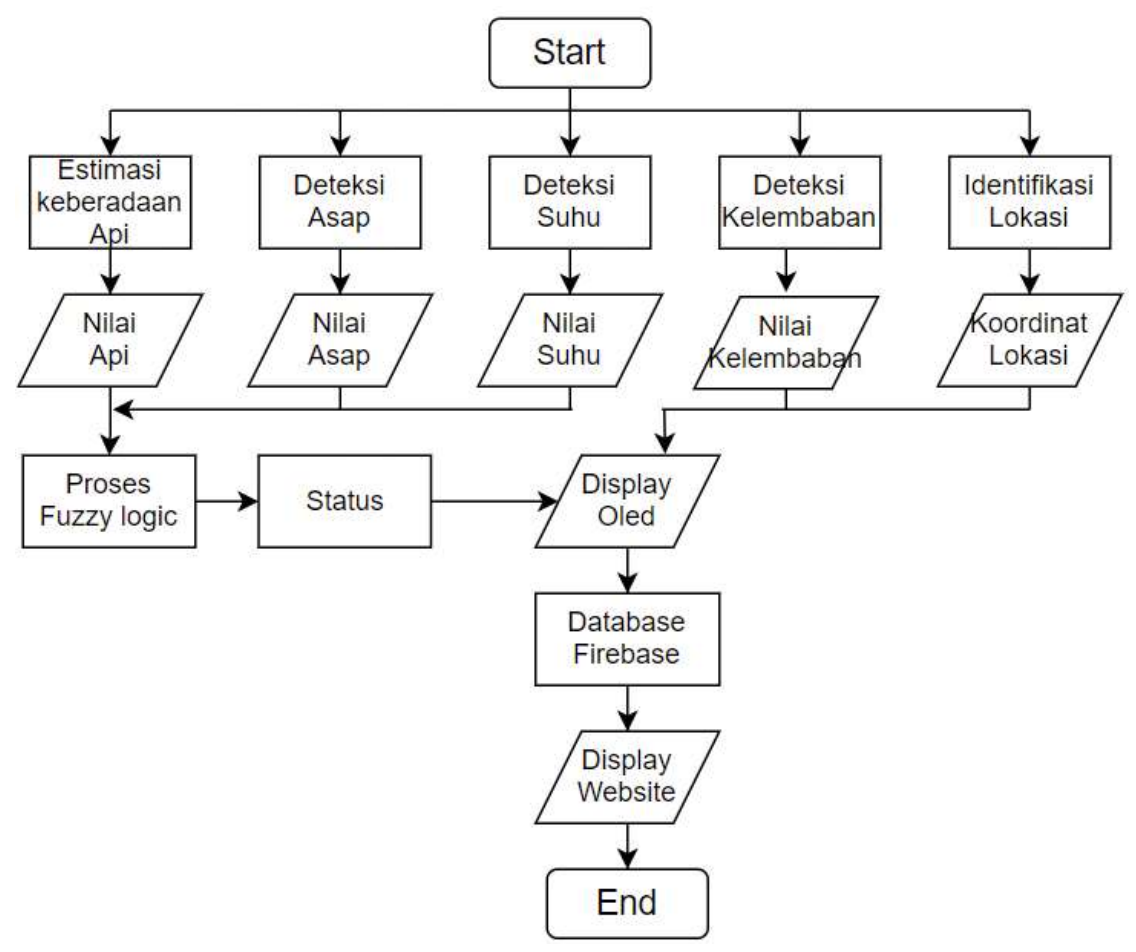

\section{Gambar 11. Flowchart Penggunaan Sistem Pendeteksi Kebakaran}

\subsection{Pengujian Nilai Kesalahan Pada Flame Sensor}

Pada pengujian ini, setiap flame sensor dilakukan pengujian sebanyak 5 kali untuk melihat kesalahan ketepatan data flame sensor yang dikirim ke Firebase Realtime Database dengan data yang didapat oleh Haridware yang ditampilkan melalui Serial Monitor dalam mendeteksi Api. Pengujian kesalahan ketepatan data flame sensor seperti Tabel 3 berikut:

Tabel 3. Pengujian Kesalahan Ketepatan Data Flame Sensor

\begin{tabular}{|c|c|c|c|c|}
\hline Flame Sensor & Condition & Firebase Realtime & Serial Monitor & Result \\
\hline 1 & Yes & 1 & 1 & Sesuai \\
\hline & No & 0 & 0 & Sesuai \\
\hline 2 & Yes & 1 & 1 & Sesuai \\
\hline & No & 0 & 0 & Sesuai \\
\hline 3 & Yes & 1 & 1 & Sesuai \\
\hline & No & 0 & 0 & Sesuai \\
\hline
\end{tabular}

Hasil pengujian kesalahan ketepatan data flame sensor sesuai dengan Tabel 3 maka nilai kesalahan ketepatan data sebesar $0 \%$. 


\subsection{Pengujian Jarak Deteksi Flame Sensor}

Pengujian jarak flame sensor terhadap objek api bertujuan untuk mengetahui jarak maksimal yang dapat dideteksi flame sensor terhadap objek api. Flame sensor telah tersambung ke NodeMCU ESP8266 dan hasil dari pengujian jarak flame sensor terhadap objek api di tampilkan pada serial monitor dan dikirim ke firebase realtime database. Pengujian dilakukan menggunakan alat bantu lilin dengan kelipatan jarak sebesar $10 \mathrm{~cm}$ hingga flame sensor tidak mendeteksi api yang terdapat pada lilin tersebut. Lilin diletakkan lurus sejajar terhadap flame sensor. Adapun hasil dari pengujian jarak flame sensor dengan api seperti pada Tabel 4 berikut:

Tabel 4. Pengujian Jarak Maksimal Flame Sensor ke Objek Api

\begin{tabular}{|c|c|}
\hline Jarak (cm) & Status \\
\hline 10 & 1 \\
\hline 20 & 1 \\
\hline 30 & 1 \\
\hline 40 & 1 \\
\hline 50 & 1 \\
\hline 60 & 1 \\
\hline
\end{tabular}

\begin{tabular}{|c|c|}
\hline Jarak (cm) & Status \\
\hline 70 & 1 \\
\hline 80 & 1 \\
\hline 90 & 1 \\
\hline 100 & 1 \\
\hline 110 & 0 \\
\hline 120 & 0 \\
\hline
\end{tabular}

Status "1" menandakan flame sensor mendeteksi adanya objek api. Status "0" menandakan flame sensor tidak mendeteksi adanya objek api. Berdasarkan Tabel 4 Pengujian jarak maksimal pada Flame Sensor dalam mendeteksi objek api sebesar $100 \mathrm{~cm}$.

\subsection{Pengujian Nilai Kesalahan Pada DHT-22}

Pengujian dilakukan dengan mengukur suhu dan kelembapan pada Dapur dengan alat pembanding Thermometer. Pengujian nilai kesalahan pada sensor DHT-22 bertujuan untuk mengetahui nilai kesalahan pembacaan suhu dan kelembapan pada sensor DHT-22 Nilai kesalahan didapatkan dengan mencari selisih kesalahan pengukuran suhu dan kelembapan pada Sensor DHT-22 dan Thermometer. Hasil pengukuran suhu dan kelembapan akan ditampilkan pada OLED Display di Hardware. Hasil pengujian kesalahan pembacaan sensor DHT-22 sesuai dengan Gambar dibawah ini:

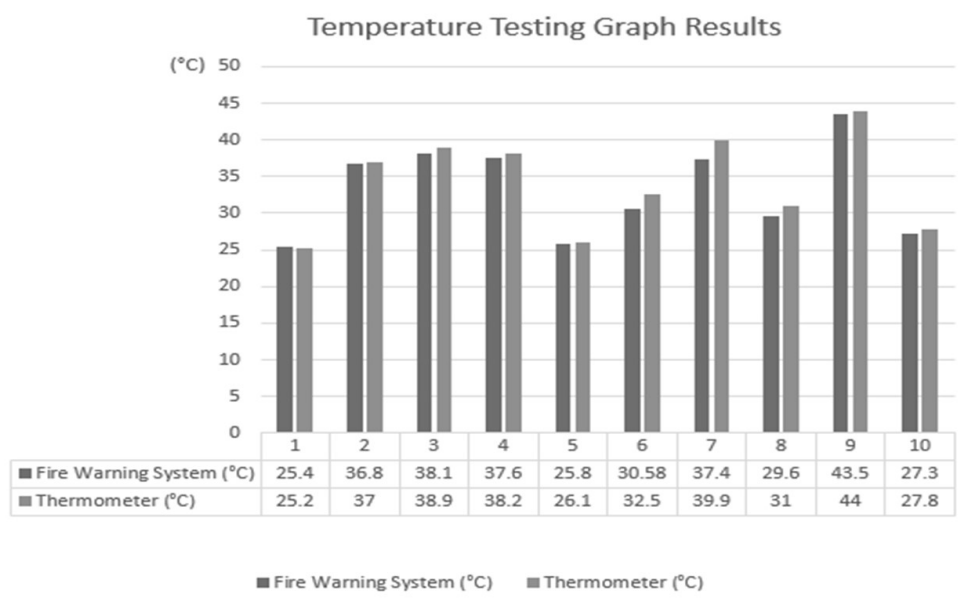

Gambar 15. Pengujian nilai kesalahan suhu pada sensor DHT-22 
Berdasarkan Gambar 15, nilai kesalahan pembacaan suhu sebesar $1.21 \%$ pada Sensor DHT22.

\subsection{Pengujian Sensor MQ-2}

Pengujian dilakukan dengan mengukur kadar asap pada ruang, kemudian dibandingkan dengan alat Smoke Detector. Pengujian ini bertujuan untuk mengetahui nilai kesalahan pembacaan asap pada sensor MQ-2. Nilai kesalahan didapatkan dengan mencari selisih kesalahan pengukuran asap pada Sensor MQ-2 dan Smoke Detector. Hasil pengukuran asap akan ditampilkan pada OLED Display di Hardware. Hasil pengujian kesalahan pembacaan sensor MQ-2 sesuai dengan Gambar 16 dibawah ini:

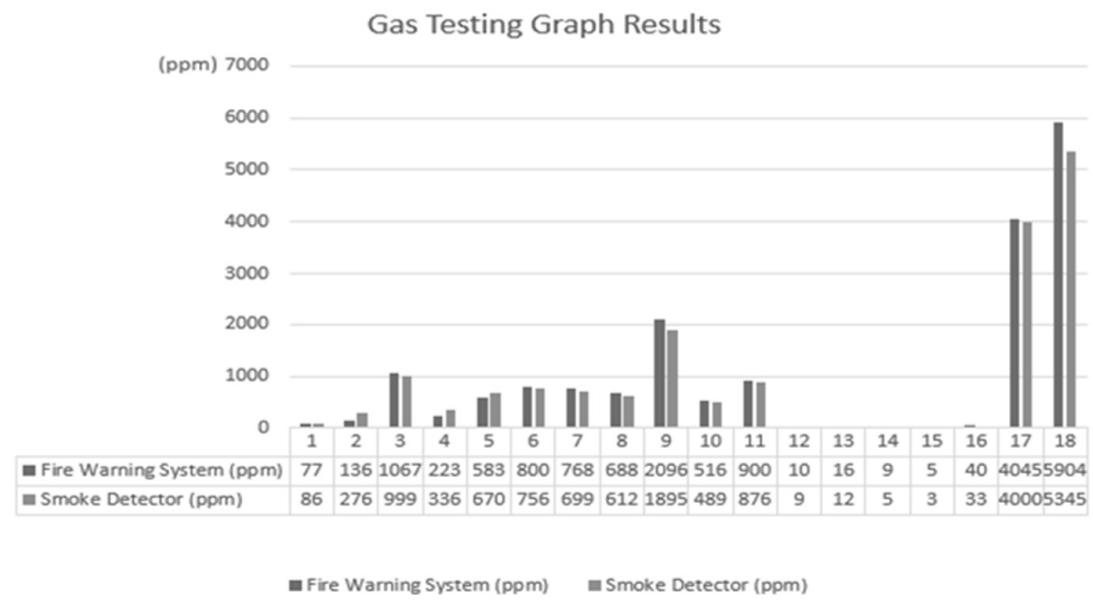

Gambar 16. Hasil pengujian pada MQ-2

Hasil yang didapatkan berdasarkan Gambar terkait Pengujian kesalahan pembacaan asap pada Sensor MQ-2 sebesar $22.19 \%$.

\subsection{Pengujian Kondisi Fuzzy}

Pengujian dilakukan dengan mengukur mendapatkan kondisi akhir dari defuzzifikasi pada Dapur. Pengujian nilai akhir kondisi fuzzy bertujuan untuk mengetahui status keamanan kebakaran. Pengujian dilakukan didalam ruangan dengan ukuran lebar 2.5 Meter, panjang 2.5 Meter dan tinggi 3 Meter, Perangkat pendeteksi kebakaran ditempelkan pada dinding ruangan, dengan posisi berada ditengah dengan ketinggian 1 Meter. Kondisi pada ruangan tersebut dibuat seolah-olah mewakili keadaan yang akan diuji, berdasarkan Fuzzy Rules Sistem Pendeteksi Kebakaran, maka pengujian dilakukan sebanyak 18 kemungkinan keadaan yang dapat terjadi, dengan menggunakan semua sensor secara bersamaan, dimana untuk setiap kemungkinan dilakukan pengujian sebanyak 10 kali. Hasil pengujian kondisi fuzzy seperti pada Tabel 8. 
Tabel 8. Pengujian Kondisi Fuzzy

\begin{tabular}{|c|c|c|c|c|}
\hline No. & Temperature $\left.\mathbf{~}^{\circ} \mathbf{C}\right)$ & Asap $(\mathbf{p p m})$ & Fuzzy Score & Status \\
\hline 1. & 23.5 & 0 & 1 & Safe \\
\hline 2. & 23.6 & 0 & 1 & Safe \\
\hline 3. & 23.8 & 0 & 1 & Safe \\
\hline 4. & 24 & 1 & 1 & Safe \\
\hline 5. & 25.7 & 10 & 1 & Safe \\
\hline 6. & 25.8 & 100 & 1 & Safe \\
\hline 7. & 27.8 & 10 & 1 & Safe \\
\hline 8. & 26.5 & 0 & 1 & Safe \\
\hline 9. & 26.7 & 5 & 1 & Safe \\
\hline 10. & 28.9 & 8 & 1 & Safe \\
\hline 11. & 31.8 & 100 & 1 & Safe \\
\hline 12. & 45.8 & 600 & 0.2 & Danger \\
\hline 13. & 52.1 & 803 & 0 & Danger \\
\hline 14. & 52.4 & 0 & 0.69 & Warning \\
\hline 15. & 54.8 & 0 & 0.51 & Warning \\
\hline 16. & 55 & 1047 & 0.5 & Warning \\
\hline 17. & 56 & 1008 & 0 & Danger \\
\hline 18. & 56.2 & 900 & 0 & Danger \\
\hline
\end{tabular}

Berdasarkan Tabel 8 didapatkan kondisi status sesuai dengan nilai akhir yang didapatkan berasal dari proses defuzzifikasi dari suhu, asap dan api. Sesuai dengan kemungkinan keadaan yang dapat terjadi sebanyak 18 keadaan.

Tabel 9. Pengujian fungsionalitas aplikasi

\begin{tabular}{|c|c|c|c|c|c|}
\hline No & Pengujian & Perlakuan & Hasil yang Diharapkan & Hasil Pengujian & Keterangan \\
\hline 1 & Sign Up User & $\begin{array}{l}\text { Masukkan email dan } \\
\text { kata sandi baru }\end{array}$ & $\begin{array}{l}\text { Berhasil menambahkan } \\
\text { akun }\end{array}$ & $\begin{array}{l}\text { Berhasil menambahkan } \\
\text { akun }\end{array}$ & Sukses \\
\hline \multirow[t]{2}{*}{2} & \multirow[t]{2}{*}{ Login User } & $\begin{array}{l}\text { Masuk dengan email } \\
\text { dan password yang } \\
\text { benar }\end{array}$ & $\begin{array}{l}\text { Masuk ke halaman } \\
\text { dashboard User }\end{array}$ & $\begin{array}{l}\text { Masuk ke halaman } \\
\text { dashboard user }\end{array}$ & Sukses \\
\hline & & $\begin{array}{l}\text { Masuk dengan email } \\
\text { dan password yang } \\
\text { salah }\end{array}$ & $\begin{array}{l}\text { Tidak dapat masuk ke } \\
\text { halaman dashboard User } \\
\text { dan Menampilkan } \\
\text { informasi email yang tidak } \\
\text { valid }\end{array}$ & $\begin{array}{l}\text { Tidak dapat masuk ke } \\
\text { halaman dashboard } \\
\text { User dan Menampilkan } \\
\text { informasi email yang } \\
\text { tidak valid }\end{array}$ & Sukses \\
\hline 3 & $\begin{array}{l}\text { User melihat } \\
\text { perangkat yang } \\
\text { terpasang di } \\
\text { rumahnya }\end{array}$ & $\begin{array}{l}\text { Login dengan user } \\
\text { email dan password }\end{array}$ & $\begin{array}{l}\text { Masuk ke halaman user } \\
\text { dan menampilkan data } \\
\text { sensor dalam bentuk } \\
\text { numerik }\end{array}$ & $\begin{array}{l}\text { Masuk ke halaman user } \\
\text { dan menampilkan data } \\
\text { sensor dalam bentuk } \\
\text { numerik }\end{array}$ & Sukses \\
\hline \multirow[t]{2}{*}{4} & \multirow[t]{2}{*}{ Login Admin } & $\begin{array}{l}\text { Masuk dengan email } \\
\text { dan password yang } \\
\text { benar }\end{array}$ & $\begin{array}{l}\text { Masuk ke halaman } \\
\text { dashboard Admin }\end{array}$ & $\begin{array}{l}\text { Masuk ke halaman } \\
\text { dashboard Admin }\end{array}$ & Sukses \\
\hline & & $\begin{array}{l}\text { Masuk dengan email } \\
\text { dan password yang } \\
\text { salah }\end{array}$ & $\begin{array}{l}\text { Tidak dapat masuk ke } \\
\text { halaman dashboard } \\
\text { Admin dan Menampilkan } \\
\text { informasi email yang tidak } \\
\text { valid }\end{array}$ & $\begin{array}{l}\text { Tidak dapat masuk ke } \\
\text { halaman dashboard } \\
\text { Admin dan } \\
\text { Menampilkan informasi } \\
\text { email yang tidak valid }\end{array}$ & Sukses \\
\hline 5 & $\begin{array}{l}\text { Admin melihat } \\
\text { seluruh lokasi } \\
\text { perangkat }\end{array}$ & $\begin{array}{l}\text { Masuk ke halaman } \\
\text { dashboard user }\end{array}$ & $\begin{array}{l}\text { Menampilkan seluruh } \\
\text { perangkat yang terpasang } \\
\text { dari seluruh user }\end{array}$ & $\begin{array}{l}\text { Menampilkan seluruh } \\
\text { perangkat yang } \\
\text { terpasang dari seluruh } \\
\text { user }\end{array}$ & Sukses \\
\hline
\end{tabular}




\subsection{Pengujian Fungsionalitas Software}

Pengujian ini dilakukan untuk mengetahui semua fitur yang terdapat pada web interface apakah berjalan dengan baik sesuai dengan fungsinya. Tahap pengujian ini dilakukan dengan cara menjalankan semua fitur yang ada di sistem tersebut. Tabel 9 menunjukkan hasil pengujian fungsionalitas software.

Dari seluruh skenario pengujian dapat diketahui bahwa aplikasi website yang dikembangkan dapat menjalankan seluruh fungsi antar muka pengguna. Fungsi ini meliputi sign up pengguna baru, login aplikasi, dan mengakses data sensor. Pada fungsi login, aplikasi mampu melakukan proses otentikasi pengguna. Jika pengguna memasukkan email dan password dengan benar maka pengguna mendapatkan akses dan sebaliknya jika salah maka aplikasi tidak mengijinkan pengguna untuk mengakses data. Pada fungsi identifikasi pengguna, aplikasi mampu membedakan hak akses baik user umum atau admin. Ini ditunjukkan pada saat keduanya telah berhasil login, terlihat pada laman dashboard dimana admin mempunyai akses penuh terhadap data.

\subsection{Pengujian Delay Monitoring Data}

Pengujian ini dilakukan agar dapat mengetahui delay ketika terjadi perubahan data pada saat dilakukan monitoring data. Pengujian ini dilakukan dengan cara menghitung rentang waktu antara perubahan data pada display perangkat dengan perubahan data pada aplikasi website. Pada pengujian ini digunakan koneksi Wi-Fi dengan bandwidth 20 Mbps. Hasil pengujian ditunjukkan pada Tabel 10 berikut.

Tabel 10. Pengujian Delay Monitoring Perangkat

\begin{tabular}{|c|c|c|c|c|c|}
\hline Pengujian & Data & Nilai Awal & $\begin{array}{l}\text { Perubahan } \\
\text { Data }\end{array}$ & Nilai Akhir & Delay (Detik) \\
\hline \multirow{4}{*}{1} & Temperature & 20 & \multirow{4}{*}{ lya } & 22 & \multirow{4}{*}{0.9} \\
\hline & Humidity & 50 & & 50 & \\
\hline & Smoke & 5 & & 5 & \\
\hline & Fire & 0 & & 0 & \\
\hline \multirow{4}{*}{2} & Temperature & 25 & \multirow{4}{*}{ lya } & 27 & \multirow{4}{*}{0.8} \\
\hline & Humidity & 55 & & 57 & \\
\hline & Smoke & 200 & & 220 & \\
\hline & Fire & 0 & & 0 & \\
\hline \multirow{4}{*}{3} & Temperature & 27 & \multirow{4}{*}{ lya } & 28 & \multirow{4}{*}{0.6} \\
\hline & Humidity & 57 & & 58 & \\
\hline & Smoke & 220 & & 230 & \\
\hline & Fire & 0 & & 1 & \\
\hline \multirow{4}{*}{4} & Temperature & 28 & \multirow{4}{*}{ Iya } & 33 & \multirow{4}{*}{0.5} \\
\hline & Humidity & 58 & & 60 & \\
\hline & Smoke & 230 & & 270 & \\
\hline & Fire & 1 & & 0 & \\
\hline \multirow{4}{*}{5} & Temperature & 33 & \multirow{4}{*}{ lya } & 34 & \multirow{4}{*}{0.3} \\
\hline & Humidity & 60 & & 60 & \\
\hline & Smoke & 270 & & 255 & \\
\hline & Fire & 0 & & 0 & \\
\hline \multicolumn{5}{|c|}{ Rata-Rata Delay } & 0.62 \\
\hline
\end{tabular}

Dari scenario pengujian sebagaimana disajikan pada Tabel 10, dapat diketahui bahwa sistem ini dapat bekerja secara real-time dalam menjalankan fungsi perubahan data. Dengan kecepatan internet $20 \mathrm{Mbps}$, delay yang dihasilkan dalam proses pengiriman data adalah kurang dari 1 detik dengan rata-rata 0.62 detik untuk seluruh pengujian. Dalam pengiriman 
dan penerimaan data pada sistem monitoring ini dapat kita ketahui masih terdapat delay, namun demikian delay yang dihasilkan relatif rendah ( $<1$ detik) sehingga proses monitoring atau perubahan data tetap dapat dilakukan secara real-time.

\section{KESIMPULAN}

Pada studi ini telah dirancang sebuah sistem pendeteksi dan monitoring kebakaran pada ruangan dengan aplikasi online. Sistem yang diusulkan menggunakan sejumlah sensor mencakup sensor asap MQ-2, sensor suhu dan kelembapan DHT-22 dan flame sensor dengan NodeMCU sebagai pusat kontrol. Informasi suhu, kelembapan, asap dan keberadaan api dikirimkan ke cloud database. Informasi tersebut kemudian dapat diakses secara online melalui aplikasi web yang dikembangkan. Dari scenario pengujian yang telah diperform, sistem ini dapat mendeteksi api dengan jarak hingga $100 \mathrm{~cm}$ dengan akurasi mencapai 100\%. Pengujian sensor suhu menunjukkan akurasi $98,79 \%$, sementara itu detector asap mengenerate akurasi $77,81 \%$. Sistem ini mampu mengirimkan data dengan rata-rata delay transmisi 0.62 detik. Parameter-parameter tersebut kemudian menjadi masukan fuzzy logic untuk pengambilan keputusan apakah aman, warning atau bahaya. Sistem yang diusulkan ini diharapkan dapat memberikan keamanan dan kemudahan pemantauan pada lingkungan rumah.

\section{DAFTAR RUJUKAN}

Addawiyah, A. S., \& Windraswara, R. (2016). Pengembangan Risk Assessment Dalam Evaluasi Manajemen Penanggulangan Kebakaran Melalui Fault Tree Analysis. Unnes Journal of Public Health, 5(1), 36. https://doi.org/10.15294/ujph.v5i1.9702

Cahyadi, W., Sa'id, M. F., \& Chaidir, A. R. (2020). Optimasi Racing Line pada ECU (Electronic Control Unit) Mobil Listrik Berbasis Fuzzy Logic Control. ELKOMIKA: Jurnal Teknik Energi Elektrik, Teknik Telekomunikasi, \& Teknik Elektronika, 8(2), 454. https://doi.org/10.26760/elkomika.v8i2.454

Damanik, I. A. verry, Suratmadji, S., \& K, A. J. (2020). Monitoring Energi Secara Real-Time pada Mesin Berbasis IoT. Jurnal Teknologi Bahan Dan Barang Teknik, 10(1), 1-8. https://doi.org/10.37209/jtbbt.v10i1.160

Farokhi, M. R. (2019). Sistem Deteksi Dan Pemadam Kebakaran Menggunakan Multi Sensor Berbasis Sim 800I. In Universitas Teknologi Yogyakarta. https://doi.org/10.22201/fq.18708404e.2004.3.66178

Hartawan, I. N. B., \& Sudiarsa, I. W. (2019). Analisis Kinerja Internet of Things Berbasis Firebase Real-Time Database. Jurnal RESISTOR (Rekayasa Sistem Komputer), 2(1), 617. https://doi.org/10.31598/jurnalresistor.v2i1.371

Hidayat, M. R., Christiono, C., \& Sapudin, B. S. (2018). Perancangan Sistem Keamanan Rumah Berbasis Iot Dengan Nodemcu Esp8266 Menggunakan Sensor Pir Hc-Sr501 Dan Sensor Smoke Detector. Kilat, 72 ), 139-148. https://doi.org/10.33322/kilat.v7i2.357

Juanita, S., \& Windarto. (2017). Rancangan sistem informasi peringatan dini bencana banjir. 
Prosiding Seminar Nasional Multi Disiplin IImu \& Call For Papaer UNISBANK Ke-3, 3, 123-129.

Dinas Kebakaran. (2017). Data Kebakaran Kota Bandung. Dinas Pencegahan Dan Penanggulangan Kebakaran Kota Bandung.

Muhammad Imamuddin, Z. (2019). Sistem Alarm Dan Monitoring Kebakaran Rumah Berbasis Nodemcu Dengan Komunikasi Android. Voteknika, 72 ), 40-45.

Nusa, T., Sompie, S. R. U. A., \& Rumbayan, E. M. (2015). Sistem Monitoring Konsumsi Energi Listrik Secara Real Time Berbasis Mikrokontroler. E-Jurnal Teknik Elektro Dan Komputer, 4(5), 19-26.

Pande Agustiana Putra, I. W., Piarsa, I. N., \& Suar Wibawa, K. (2018). Sistem Pendeteksi Kebakaran Menggunakan Raspberry Pi Berbasis Android. Jurnal Ilmiah Merpati (Menara $\begin{array}{lllll}\text { Penelitian Akademika Teknologi Informasi), } & 67 .\end{array}$ https://doi.org/10.24843/jim.2018.v06.i03.p03

Prihatmoko, D. (2018). Perancangan Sistem Monitoring Perangkat Elektronik Rumah Menggunakan Internet. Simetris: Jurnal Teknik Mesin, Elektro Dan IImu Komputer, 9(1), 279-286. https://doi.org/10.24176/simet.v9i1.2041

Rahmat, F. Al, Sunarya, U., \& Tulloh, R. (2018). Prototipe Robot Kapal Pengukur Tingkat PH dan Turbiditas Air Berbasis Metode Modified Fuzzy. Jurnal Rekayasa Elektrika, 14(1), 43-50. https://doi.org/10.17529/jre.v14i1.9771

Rizal, R., \& Karyana, I. (2019). Innovation in Research of Informatics ( INNOVATICS) Sistem Kendali dan Monitoring pada Smart Home Berbasis Internet of Things ( IoT ). 2, 4350.

Satriatama, R., Darlis, D., \& Pangaribuan, P. (2020). Sistem Kontrol Troli Rotari sebagai Tempat Penitipan Barang Otomatis menggunakan Fuzzy Logic. ELKOMIKA: Jurnal Teknik Energi Elektrik, Teknik Telekomunikasi, \& Teknik Elektronika, 8(3), 575. https://doi.org/10.26760/elkomika.v8i3.575 